\title{
Bleeding due to ectopic varices in a urinary diversion: A multidisciplinary diagnostic and therapeutic challenge
}

\author{
Eduardo Mariano Albers Acosta, $M D^{\prime}$; Alfonsi Friera Reyes, $M D^{2}$; Ricardo Brime Menéndez, $M D^{1}$
}

'Department of Urology, Hospital Universitario de La Princesa, Madrid, Spain. Universidad Autónoma de Madrid, '2Department of Interventional \& Vascular Radiology, Hospital Universitario de La Princesa, Madrid, Spain, Universidad Autónoma de Madrid.

Cite as: Can Urol Assoc J 2015;9(11-12):E897-9. http://dx.doi.org/10.5489/cuai.3175

Published online December 14, 2015.

\section{Abstract}

The ectopic varices in patients with portal hypertension are those that occur at any level of the gastrointestinal (GI) tract, regardless of the varices that occur at the esophageal level. These ectopic varices account for $2-5 \%$ of the causes of GI bleeding varices. The risk of bleeding is quadrupled compared to the esophagogastric area, with a mortality of up to $40 \%$. The transjugular intrahepatic portosystemic shunt, should be considered in cases secondary to recurrent bleeding varices.

We present a case report of an urological emergency of bleeding in a urinary diversion secondary to ectopic varices successfully treated through the placement of transjugular intrahepatic portosystemic shunt. The condition described here is rare, but important, as it can be a life-threatening complication of portal hypertension. This kind of complication should be known by urologic surgeons managing patients with urinary diversions.

\section{Introduction}

In patients with portal hypertension, the most common site of varices is at the esophageal level. ${ }^{\text {' Secondary varices }}$ occur at any level of the $\mathrm{Gl}$ tract, accounting for $2-5 \%$ of the cases of $\mathrm{Gl}$ varices. However, in the latter cases, the risk of bleeding is quadrupled, compared to those located at the esophagogastric area, with a mortality of up to $40 \%,{ }^{2}$ thus, becoming a diagnostic and therapeutic challenge. ${ }^{3}$

The main clinical manifestation in patients with portal hypertension and ectopic varices, who are carriers of an ileal conduit, is bleeding at the stomal location, mainly at the mucocutaneous junction. ${ }^{4,5}$ The bleeding episodes are usually intermittent and may imply vital compromise due to their recurrent nature and intensity within short periods of time. Treatment includes local measures to stop the bleed- ing (local compression, sclerotherapy, and endoscopic band ligation) whenever possible. ${ }^{6,7}$ However, while these measures solve the acute stage, they don't decrease the risk of recurrence of the bleeding. ${ }^{8}$ Transjugular intrahepatic portosystemic shunt (TIPS), selective embolization, or surgical shunt solutions should be considered in cases of recurrent bleeding varices. ${ }^{8,9}$ The first of the aforementioned measures is currently accepted as one of the methods of choice.

Few cases have been reported of ectopic varicose bleeding at the ileal conduit in patients who have undergone cystectomy with uretero-ileal diversion. ${ }^{10}$ We report a case of successful treatment of bleeding from an ectopic varicose vein in the Bricker's loop by TIPS.

\section{Case report}

A 74-year-old man with known chronic liver disease underwent radical cystectomy with Bricker's urinary diversion due to infiltrating urothelial and multifocal in situ bladder carcinoma. Nine months after the surgical procedure, he was admitted to the emergency room because of bleeding in the stomal outer margin, which was controlled by local handling (compression and cauterization). A few days later, he returned to the emergency room with renewed acute bleeding at the Bricker's loop site; poor general conditions, accentuated mucocutaneous pallour, hemodynamic instability (blood pressure [BP]: 65/45 mmHg; heart rate [HR]: 110 bpm), anemia (hemoglobin: $5.2 \mathrm{~g} / \mathrm{dL}$ ) and thrombocytopenia. Once stabilization was accomplished with fluid and blood transfusions, thorough examination revealed a swollen stoma and bloodless urine flow, with a major bleeding site close to the stomal edge that was successfully controlled by inserting a Foley catheter in the loop's lumen and filling the balloon to compress the vein.

A followup computed tomography (CT) revealed an unknown important portal hipertensión in the venous phase, affecting the territory of the ileal conduit and with dilated 
Albers et al.

varicose veins accounting for the bleeding (Fig.1). Betablockers were initially indicated, but given the lack of total control of the bleeding and its recurrence while interned, it was decided that TIPS should be implemented (Fig.2). Fluoroscopy before the TIPS showed varicose stomal veins and a shunt to the abdominal wall (Fig.3). Posterior to its performance, there were no episodes of bleeding during the period of hospitalization and at the time of discharge two weeks later, the clinical and analytical parameters were normal. He remains symptomless at the time of this report.

\section{Discussion}

Several lines of approach for acute bleeding of varices have been described, such as local measures of hemostasis (stitches on bleeding sites, silver nitrate cauterization). The endoscopic sclerotherapy, a technique that has been demonstrated in a review of cases series, can cause mucosal ulceration, stomal retraction, stenosis, and necrosis. ${ }^{1,3}$ The use of beta-blockers as monotherapy in secondary prophylaxis does not reduce the risk of recurrence. ${ }^{3}$ Selective embolization is effective in the acute phase in $94 \%$ of patients, however, the formation of a collateral venous network surrounding the previously treated loci may trigger a new episode of bleeding. ${ }^{8}$

Although all these measures may help solve the acute phase, they do not decrease the risk of hemorrhagic recurrence and its severity; thus, the need to evaluate other, more effective end treatments are deemed necessary. Although more invasive than the treatments mentioned above, measures such as portacaval shunt surgery and placement of TIPS present a higher rate of definitive solution.

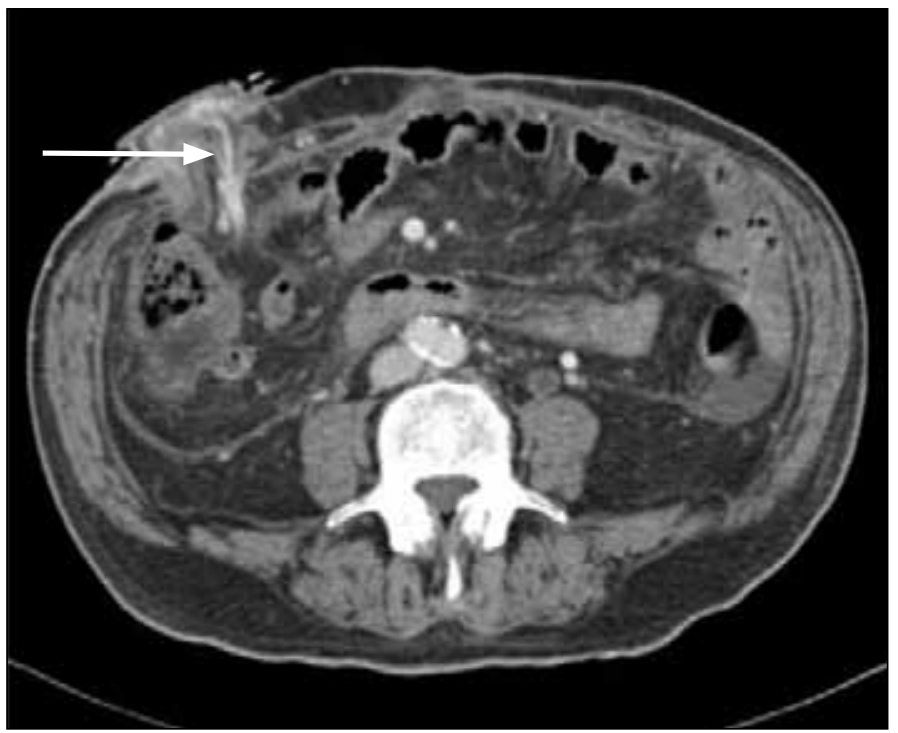

Fig. 1. Abdominal CT showing varicose veins in the stoma.
Portacaval shunt surgery may be effective for solving such cases, however, the fact that it is an invasive method presents an added risk to the patient. Alternatively, TIPS, being a less invasive procedure, may be the method of choice. A case series has shown that the rate of rebleeding as a complication following TIPS is close to $23 \% .{ }^{8}$ Some studies show that the performance of simultaneous selective embolization and TIPS may also be an effective alternative. ${ }^{1,2,8}$

\section{Conclusions}

Bleeding due to ectopic varices at a Bricker's ileal conduit presents a diagnostic and therapeutic challenge for urologists. Because of its potential recurrence and severity, a delay in taking action can quickly lead to a fatal outcome. Thus, in carriers of portal hypertension, it is important to consider these potential complications. TIPS is a safe and effective procedure. ${ }^{10}$ The urologist should consider it first-line of in handling patients with portal hypertension associated with bleeding unresponsive to local measures.

Competing interests: The authors declare no competing financial or personal interests.

This paper has been peer-reviewed.

\section{References}

1. Helmy FA, Al Kahtani K, Al Fadda M, et al. Updates in the pathogenesis, diagnosis and management of ectopic varices. Hepatol Int 2008;2:322-34. http://dx.doi.org/10.1007/s12072-008-9074-1

2. Saad WAE, Lippert A, Saad NE, et al. Ectopic varices: Anatomical classification, hemodynamic classification and hemodynamic- based management. Tech Vasc Interv Radiol 2013;16:158-75. http://dx.doi. org/10.1053/.t.tvir.2013.02.004

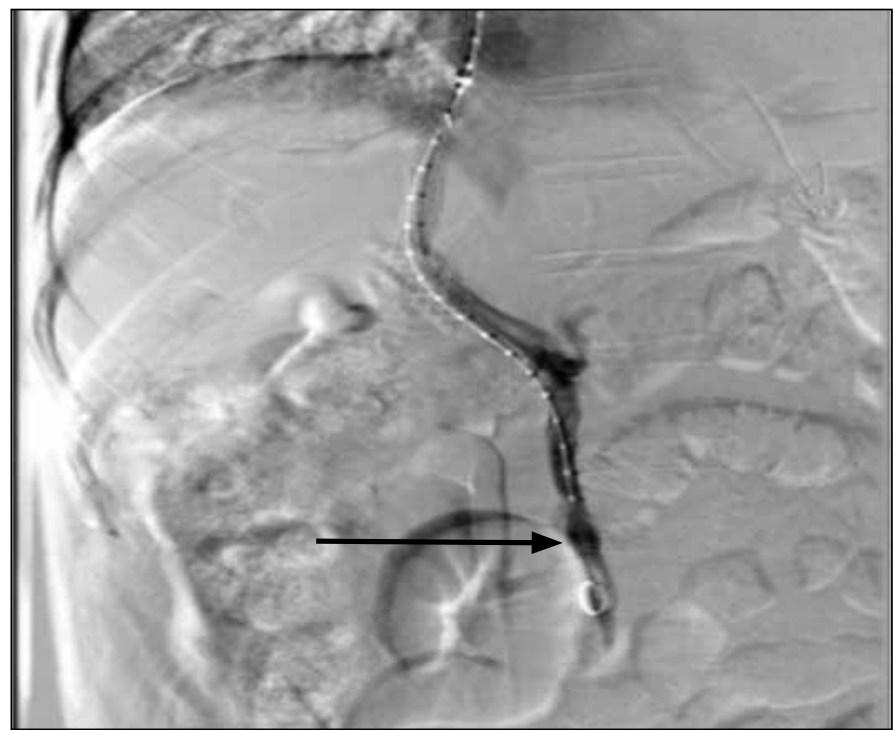

Fig. 2. TIPS placement. Contrast injection through the superior mesenteric vein, showing the bypass towards the superior vena cava. 


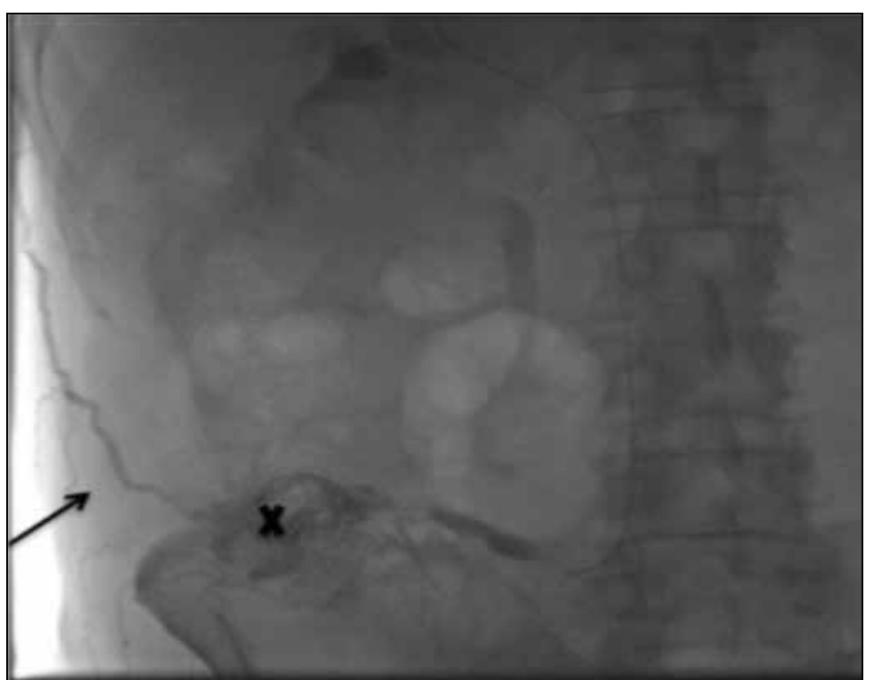

Fig. 3. Fluoroscopy before the TIPS showed varicose stomal veins (marked by $\mathrm{X}$ ) and the shunt to the abdominal wall (arrow).
3. Spier BJ, Fayyad AA, Lucey MR, et al. Bleeding stomal varices: Case series and systematic review of the literature. Clin Gastroenterol Hepatol 2008;6:346-52. http://dx.doi.org/10.1016/i.cgh.2007.12.047

4. Christodoulou D, Tsianos EV, Kortan P, et al. Gastric and ectopic varices - newer endoscopic options. Ann of Gastroenterol 2007;20:95-109.

5. Mitach A, Gbenou MG, Rashed S, et al. Secondary recurrent haemorrhage with peristomal varices complicating a urinary derivation according to Bricker and treated efficiently by endoscopic way. Prog Urol 2012; 22:127-31. http://dx.doi.org/10.1016/i.purol.2011.04.010

6. Kabeer MA, Jackson J, Widdison AL, et al. Stomal varices: A rare cause of stomal hemorrhage. A report of three cases. Ostomy Wound Manag 2007:53:20-8

7. Roberts PL, Martin FM, Schoetz DJ Jr., et al. Bleeding stomal varices. The role of local treatment. Dis Colon Rectum 1990; 33:547-9. http://dx.doi.org/10.1007/BF02052204

8. Vidal V, Joly L, Perreault $P$, et al. Usefulness of transjugular intrahepatic portosystemic shunt in the management of bleeding ectopic varices in cirrhotic patients. Cardiovasc Intervent Radiol 2006; 29:216-9. http://dx.doi.org/10.1007/s00270-004-0346-4

9. Shibata D, Brophy DP, Gordon FD, et al. Transjugular intrahepatic portosystemic shunt for treatment of bleeding ectopic varices with portal hypertension. Dis Colon Rectum 1999;42(12):1581-5. http:// dx.doi.org/10.1007/BF02236211

10. Biecker E. Portal hypertension and gastrointestinal bleeding: Diagnosis, prevention and management. World J Gastroenterol 2013;19: 5035-50. http://dx.doi.org/10.3748/wig.v19.331.5035

Correspondence: Dr. Albers Acosta Eduardo Mariano, Department of Urology, Hospital Universitario de La Princesa,Madrid, Spain; eduardoalbers15@gmail.com 